\title{
A Review of Recent Forest and Wildland Fire Management Decision Support Systems Research
}

\author{
David L. Martell ${ }^{1}$
}

Published online: 19 April 2015

(C) Springer International Publishing AG 2015

\begin{abstract}
This is a review of recent efforts to develop and implement forest and wildland fire management decision support systems (FMDSS) that fire managers can use to enhance their management of their fire suppression activities. Fire managers need to resolve complex decisions associated with fuel management, fire prevention, detection, the suppression of potentially destructive wildfires and the use of prescribed fire to achieve an appropriate balance between the beneficial and detrimental social, economic and ecological impacts of fire on flammable landscapes, often under considerable uncertainty. This review focuses on the use of operational research and management science (OR/MS) methods to address their suppression resource management decision support needs.
\end{abstract}

Keywords Wildland fire - Wildfire - Operational research . Management science $\cdot$ Suppression resource management . Optimization $\cdot$ Planning under uncertainty

\section{Introduction}

Most forest and wildland fire research can be classified as belonging to one or more of the following four categories:

1. Fire behaviour or the physics and chemistry of fire ignition and spread.

This article is part of the Topical Collection on Fire Science and Management

David L. Martell

david.martell@utoronto.ca

1 Faculty of Forestry, University of Toronto, 33 Willcocks St., Toronto, ON M5S 3B3, Canada
2. Fire ecology which deals with the ecological impacts of fire.

3. The human dimensions of wildland fire which addresses the socio-economic impact of fire.

4. Fire management systems that deal with fire management processes, decision-making and planning.

This is a review of recent developments in fire management systems, the use of operational research and management science (OR/MS) methods to develop fire management decision support systems (FMDSS) that fire mangers can use to enhance their decision-making. The spatial and temporal focus of this review is very decidedly North America for the period 2010 through 2014. Wildland fire and the development and use of FMDSS span the globe but the vegetation that fuels fire, weather, topography, land use and land management practices vary around the globe (see, for example, Scott et al. (2014) [1]) as do the fire management policies, organizations, technology and practices that have evolved to manage fire on those very diverse landscapes. I have drawn upon my understanding of fire management in Canada to structure my review and apologize in advance to readers that recognize that the fire management that is practised across, for example, the sparsely populated boreal forest region of Canada where fire managers make extensive use of aircraft, differs very significantly from what happens in heavily populated wildland urban interface (WUI) areas in other countries where fire mangers rely on fire engines, dozers and other heavy equipment.

That most of the articles reviewed here pertain to North America reflects the fact that much of the recent FMDSS research was focussed on North America but that was not always the case, nor will it remain so in the future. Many of the important contributions from the former Soviet Union are reviewed in Martell (1982) [2]. Growing interest in the development and use of FMDSS across Europe is evident in the 
growth in publications that deal with FMDSS that focus on that area beginning primarily in the first decade of the $21 \mathrm{st}$ century (e.g. Kalabokidis et al. (2002) [3] and Rachaniotis and Pappis (2006) [4•]), some of which were reviewed by Minas et al. (2012) [5]. Given the very significant investments in fire research in Europe in recent years, Pacheco et al. (2013) [6] is but one example of many more publications dealing with FMDSS in Europe that can be expected to appear in the literature in the coming years. Interest in FMDSS has also grown significantly in Australia in recent years and as is the case with Europe, Plucinski (2013) [7] is no doubt a pre-cursor of many important contributions that will emanate from there in the coming years.

The application of OR/MS methods to fire management dates back to the pioneering work of Shephard and Jewell (1961) [8] in the Operations Research Center at the University of California, Berkeley. Many of the publications that dealt with OR/MS and FMDSS published during the period 1961 through 1981 were reviewed by Martell (1982) [2], Martell et al. (1998) [9] and Martell (2007) [10] reviewed subsequent publications as did Minas et al. (2012) [5] who more recently approached fire management from a methodological perspective and discussed the applicability of specific OR/MS methods (e.g. mathematical programming, simulation and stochastic programing) to fire management decisionmaking problems. The expanding scope of OR/MS applications in fire management and methodological advances such as, for example, the development of new methods for dealing with uncertainty, have also spawned more specialized reviews such as Miller and Ager's (2013) [11] recent review of risk analysis in forest and wildland fire management.

\section{Overview}

Forest and wildland fire are natural ecosystem processes, but fire can and often does pose significant threats to public safety, property and forest resources. That creates special challenges for fire managers that are charged with the responsibility for achieving an appropriate balance between the beneficial and detrimental impacts of fire. Sound fire management calls for fuel management, fire prevention and detection, the suppression of potentially destructive wildfires, modified suppression of some wildfires, allowing some beneficial wildfires to burn, and the use of prescribed fire to achieve ecosystem management objectives. This review focuses on fire management decision-making and the development and use of FMDSS that fire mangers can use to enhance the cost-effectiveness of their fire suppression activities.

Most North American forest and wildland fire management agencies were created in the early decades of the 20th century in response to large destructive fire incidents that took many lives and destroyed many homes and natural resources. Those catastrophic losses led to the formation of fire control agencies and the widespread adoption of fire exclusion policies that were based on the belief that fire was a destructive force that could and should be excluded from the forest at almost any cost (see Pyne (1982) [12] and Pyne (2007) [13]). Beginning in the 1970s, many of those agencies slowly began to evolve from fire control agencies designed to practise fire exclusion, towards fire management organizations fuelled by growing recognition of the need to achieve an appropriate balance between mitigating the destructive impact of fire while reaping its benefits, all at a reasonable cost. That shift has, for most agencies, been understandably gradual for many complex ecological, social, legal and cultural reasons that are well beyond the scope of this review. That slow pace of change is also, no doubt, due in part, to a lack of proven FMDSS which often leaves fire mangers to practise what might best be described as "when in doubt - put it out" fire management.

Since the destructive impact of wildfires usually increases with fire size and the growth in the area of a free-spreading fire is a non-linear non-decreasing function of time, forest and wildland fire managers share with other emergency response organizations, a need to quickly detect and respond to incidents. The focus of this review is fire suppression effectiveness but one cannot nor should one attempt to focus on what takes place on the fire line alone, in isolation from the many other activities that take place in a fire organization and influence the cost-effectiveness of its suppression systems. In order to mitigate the destructive impact of fire, one must devote efforts to modifying flammable fuel complexes (fuel management), reducing the number of human-caused fires that occur (prevention), detecting potentially destructive fires such that they can be contained at a small size at a reasonable cost (detection), acquiring, deploying and dispatching initial attack resources such as airtankers, transport helicopters, engines and fire fighters such that they can reach destructive fires soon after they are reported (suppression resource acquisition, deployment, dispatch and use), and mobilizing incident management teams to deal with the fires that escape initial attack (large fire management).

Forest and wildland fire management can be viewed from a supply chain management perspective (see Martell (2007) [10]) and defined as delivering the right amount of the right fire to the right place at the right time at the right cost, and this review deals with decision-making and planning concerning the suppression aspects of the forest and wildland fire management supply chain. That being said, space limitations preclude the inclusion of a detailed discussion of all of the suppression aspects of a modern fire management programme. This review does not, for example, explore the development of decision support systems that can be used to help determine when, where and how best to carry out fuel management treatments, an important aspect of fire suppression that is reviewed in depth by Dr. P. Omi in another review in this issue. Although the need to grow some wildfires to achieve 
ecosystem benefits is touched upon very briefly, the development and use of FMDSS to enhance the use of prescribed fire are not covered.

\section{Prevention}

The primary objective of the fire prevention system is to reduce human-caused fire occurrence. Fire prevention specialists refer to the "three E's of prevention", engineering, education and enforcement. There are very few recent publications that describe FMDSS that fire managers can use to help decide how they might best allocate their prevention resources to reduce human-caused fire occurrence, and publications that deal with the enforcement aspect of prevention are notable for their absence. Since wildland fire arson is a problem in many jurisdictions (see for example, Prestemon et al. (2010) [14•] and Ager et al. (2014) [15]), it is surprising that a search of the recent literature revealed no publications that build on the early efforts of Heineke and Weissenberger (1974) [16] who explored the properties of optimal deterrence policies.

Most recent wildland fire publications that address the engineering aspects of prevention deal with fuel management. Prestemon et al. (2010) [14•] identified "a striking absence" of studies that document the effectiveness of wildfire prevention education (WPE) measures. They used econometric methods to develop a statistical model that relates human-caused fire occurrence to prevention education activities and other factors (e.g. fire weather) in the state of Florida. They then used their model to carry out a benefit cost analysis of WPE and found that at the state level, WPE benefits significantly outweigh their costs.

\section{Detection}

The objective of the fire detection system is to deliver fires to the initial attack system in a timely and cost-effective manner. Put simply, it should deliver fires to the initial attack system while they are small and easily controlled but at a reasonable cost. Over-investment in the detection system at the expense of the initial attack system will deliver small fires that may escape initial attack due to a shortage of initial attack resources. Similarly, enhancing the initial attack system at the expense of the detection system will result in the detection system delivering large, difficult to control fires to the initial attack system. Detection and initial attack system planning must be integrated to achieve an appropriate balance to achieve overall fire management objectives.

Most fire management agencies rely on a mix of detection resources that may include the use of fixed lookout towers that are staffed by observers and/or are equipped with digital cameras or other sensors, detection patrol aircraft, satellites and the public that reports fires they detect as they travel near or through forested areas. Although some fire management agencies use satellites to monitor fires in remote areas, the satellite technology currently available to fire management agencies is such that the sizes at which new fires will be delivered to the initial attack system preclude their use for detection anywhere other than in remote areas where fires pose little or no threat to public safety and forest resources.

Fire managers must decide where to establish towers, when to staff or activate them and when and where to route aerial detection patrols. Mees (1976) [17] addressed the tower location problem and Kourtz (1973) [18] the aerial detection patrol routing problem, many years ago. Recent years have witnessed enormous growth in interest and publications that deal with the remote sensing and image processing systems designed to be used for wildland fire detection purposes. Mahdipour and Dadkhah (2014) [19] for example, reviewed recent publications that deal with wireless fire sensor networks. Koltunov et al. (2012) [20] described the methodology they developed for evaluating the timeliness of the initial detections of fires by the GOES satellite which they report, did detect a few incidents "even before the initial reports from conventional sources" in California in 2006. Many authors have recently investigated the use of image processing technology to model satellite (e.g. Benkraouda et al. (2014) [21]) and digital camera (Ko et al. (2012) [22]) fire detection processes.

Matthews et al. (2012) [23] report on their testing of two image-based sensors mounted on towers in Australia, but the recent literature contains very few publications that deal with fire detection decision support systems. That absence may reflect the fact that the tower location models and patrol routing models developed in the past have long since been implemented and that further research is felt to be no longer required, but I am aware of no convincing evidence that the decision support needs of detection managers have been adequately addressed. One notable exception is Tapia and Castillo (2014) [24] who describe their development of a topographic index that they used to evaluate alternative tower locations with respect to potential fire occurrence and damage and their use of spatial analysis methods to minimize the number of towers required to achieve specified coverage levels.

With the exception of Rego and Catry's (2006) [25•] lookout tower detection probability model, there appears to be little current interest in anything other than the potential use of satellites and fixed cameras for fire detection. It is not clear that the satellite technology available to fire managers will prove to be practical for detection purposes in the near future. It is, however, reasonable to assume that the use of drones to map large fires from the restricted air space fire management agencies impose over large active fires will increase and that they will eventually be used for aerial detection patrols currently flown using piloted fixed-wing aircraft. Assuming that will be the case, it is essential that $\mathrm{OR} / \mathrm{MS}$ specialists resurrect the 
important early detection patrol routing research initiated by Kourtz (1973) [18]. It is also important that sound methods be developed for evaluating the performance of detection systems that reach well beyond simple measures such as fire size at detection and the fraction of fires detected and reported by aerial detection patrol aircraft, lookout tower observers and camera-based systems. The fact that the public reports many fires in many jurisdictions is an important issue that has not been adequately addressed by detection researchers and there is a need to better determine when and where aerial detection patrol aircraft and fixed fire lookout resources should be focussed and when and where fire managers should rely upon the public.

\section{The Management of Fire Suppression Resources}

Fire management agencies use many types of resources to contain and ultimately extinguish wildfires that can be grouped into the following broad categories.

1. Fire crews equipped with hand tools, pumps, hose and other equipment they use to construct and maintain control line and to extinguish fire within the fire perimeter.

2. Airtankers and fire trucks that deliver fire retardants and/ or suppressants to fires.

3. Transport vehicles (e.g. trucks and aircraft) that are used to transport fire fighters and their equipment to and from fires.

4. Fire itself.

One could address the management of such resources from many perspectives, and this review is structured with respect to the spatial and temporal attributes of the decisions associated with their management. Strategic decision-making pertains to decisions that involve major agency-wide commitments of resources that will influence operations for long periods of time (e.g. the acquisition of airtankers that may be used for one or more years) while tactical decision-making is associated with decision-making that results in resource allocations and commitments within a smaller area over relatively short periods of time (e.g. the daily deployment of airtankers to attack bases or the sharing of fire crews for weeks). Initial attack dispatching and deciding how to contain a particular fire constitute resource commitments within a fire management unit or on a specific fire that typically persist for relatively short periods of time (and are often revised as the day progresses) are examples that are often classified as operational decision-making problems.

\section{A Need to Develop Linked Fire Management Subsystem Models}

When fire managers decide upon the composition of their airtanker fleets, they must consider where the airtankers might be home based at the beginning of each fire season, how they might be temporarily deployed and re-deployed each day as the season progresses, how they might be dispatched on initial attack each day and how the air attack officers will utilize them to contain the fires to which they are dispatched. The many decisions concerning airtanker acquisition, deployment and use are linked in a complex hierarchy and must be resolved under considerable uncertainty.

Consider, for example, the daily airtanker deployment decision. At the end of each day, fire managers must decide where to deploy their airtankers to best achieve their initial attack objectives the following day. The number and type of airtankers available for deployment each day depend upon higher-level airtanker acquisition and home-basing decisions that were resolved at the start of the fire season or perhaps even many years before, and lower-level decisions concerning how they were deployed, dispatched and used during recent days. What results from daily deployment decision-making is therefore influenced by higher-level airtanker acquisition decision-making and lower-level airtanker use decision-making. One would, in principle, like to develop comprehensive planning models that account for such linkages but it would be very difficult to develop tractable models that would address that need.

The proceedings of a 1992 workshop edited by Martell et al. (1996) [26] in which the participants explored how hierarchical approaches have and might be applied to forest management planning illustrates some of the many approaches that have been used to deal with large complex hierarchical systems. One relatively simple way of dealing with the need to develop linkages between different spatial and temporal levels is to focus on the decision-making level/problem/subsystem of primary interest, develop a model that is believed to capture the essential elements of that subsystem reasonably well and when possible, loosely coupling it with much simpler models that capture the essence of the decision-making that goes on above and below that level in the hierarchy.

\section{Strategic Management of Fire Suppression Resources}

Strategic management includes decision-making associated with the acquisition and home-basing of airtankers and transport aircraft (which may be purchased and used for many years, chartered for the fire season or chartered for short periods of time as required) and the hiring and home-basing of fire crews. One of the first documented uses of OR/MS for strategic airtanker management is Martell et al.'s (1984) [27] simulation model which was subsequently enhanced by McAlpine and Hirsch (1999) [28], modifications of which continue to be used by the Ontario Ministry of Natural Resources and Forests (OMNRF). Similar approaches have since been developed and used by others to explore the potential impact of alternative policies concerning initial attack 
resource dispatching and use, fuel management and climate change (e.g. Fried et al. (2006) [29]).

Mavsar et al. (2013) [30] is a detailed review of four strategic planning simulation models: the Leopards system which was developed and is used in the province of Ontario Canada (see McAlpine and Hirsch (1999) [28], the Chilean Kitral model (Pedernera et al. 1999 [31]), the SINAMI model which was developed in Spain and the Fire Program Analysis (FPA) system (FPA, 2015 [32]) which is used in the United States. Despite their concern that comprehensive economic measures of fire impact have yet to be fully incorporated in such systems, it appears that there are good simulation models that can be and are used for strategic planning purposes. That being said, Bruins et al.'s (2010) [33] case study of the development and use of the FPA system in the United States demonstrates a clear need to involve the fire managers that are required to use such systems more fully in the development and implementation of such FMDSS.

Some FMDSS developers have, as noted above, addressed the need for integrated planning by developing hierarchical decomposition methods that focus primarily on what takes place at one level of the decision-making hierarchy with some linkage to decisions that are resolved within, above or below the level of primary interest. Greulich (1976) [34] exploited the Markovian properties of day to day changes in fire danger rating indices to develop a mixed integer linear programming model that addressed both annual home-basing and the daily transfer of airtankers from base to base in California. More recently, MacLellan and Martell (1996) [35] developed a linear programming model that was used to help determine where to home base a known number of airtankers and how they could be re-deployed from base to base each day based on simple assumptions concerning how many airtankers would be required to be deployed on alert at each airtanker base each day.

Simulation models are descriptive models that can be used to predict what might happen if specified sets of resources are used according to specified policies and tactics, but when faced with many alternatives, they cannot explicitly or implicitly evaluate all feasible alternatives and be used to prescribe which policies and strategies might be good or optimal. In recent years, attention has therefore increasingly shifted to new approaches that exploit new developments in deterministic and stochastic optimization to develop prescriptive models. Deciding how many airtankers or fire trucks to hire and where to home base them should be influenced by the subsequent tactical decision-making concerning how they will be re-located from base to base each day as the season progresses (e.g. daily deployment) and operational decisionmaking concerning how they will be dispatched and used on individual fires as each day progresses. Although one can incorporate strategic, tactical and operational fire suppression resource decision-making under uncertainty in descriptive simulation models, it's simply not possible, given current computer and optimization technology, to develop tractable integrated stochastic optimization models that address all three levels of fire management decision-making simultaneously nor, to my knowledge, have comprehensive decomposition strategies been developed and used to address such fire management problems.

Mavsar et al. (2013) [30] point out that goal programming methods are used to aggregate local Fire Planning Unit (FPU) analysis up to the national level, but there have been few attempts (see, for example, Donovan (2006) [36]) to use optimization methods to develop strategic planning DSS that can be used to develop and evaluate alternative strategies for managing large complex fire management systems. One very important aspect of such planning is short-term suppression resource sharing. Consider for example, fire management in Canada. The federal government is responsible for fire management in national parks and some other small areas (e.g. military bases), but fire management in Canada is largely a provincial and territorial responsibility. That means there are thirteen federal, provincial and territorial agencies, each of which is further partitioned into some higher spatial resolution regional structure. Each agency must decide how to allocate its resources to each region within its jurisdiction and how those resources will be re-deployed to meet local demands as each fire season progresses. When they do so, they must consider the possibility that they may share their resources with other agencies. Put simply, when fire managers in the province of Ontario develop and evaluate alterative fire management strategies, they must consider the fact that they can and often do re-deploy their resources within the province of Ontario but they must also account for the fact that from time to time; they lend suppression resources to or borrow suppression resources from other agencies.

Unfortunately, most of the strategic FMDSS that have been developed and used do not account for the interaction of fire management agencies that participate in suppression resource sharing agreements very well. Two factors that complicate the solution of such problems are (1) the complex social, political and physical processes that govern such interaction are at best, poorly understood and (2) it would be difficult to develop tractable models that capture such interactions even if they were well understood. Magnussen and Taylor (2012) [37•] focussed on fire weather across Canada and explored spatial and temporal variation in several fire regime variables that influence the sharing of fire suppression resources across Canada. Tsang et al. (2013) [38••], on the other hand, interviewed representatives of fire management agencies and used game theory methods to develop a strategic resource sharing model which they used to study fire suppression resource sharing processes. Both highlight an urgent need to develop FMDSS to support such decision-making in large complex collaborative networks of fire management agencies 
that deal with fire on very diverse, widely disbursed landscapes and are responsible to many different political masters appointed by governments that must address the needs and expectations across very different state, provincial and national jurisdictions.

\section{Daily Deployment of Fire Suppression Resources}

Forest and wildland fire management agencies share much in common with urban fire departments, emergency medical response agencies and other first responder organizations for which response times are critical. Each day, fire mangers must predict when and where fires might occur and decide where to deploy their airtankers, fire fighters and other suppression resources to minimize the time required for the "right" resources to reach what they anticipate might be critical incidents.

Many simulation models have been developed to model the daily performance of initial attack systems. Islam and Martell (1998) [39], for example, developed a simulation model that can be used to predict the performance of an initial attack airtanker system comprised of airtankers deployed at a number of interacting bases and investigated how the system performance varies as the number of fires per day and the initial attack range varies.

Islam et al. (2009) [40•] developed a time-dependant queueing model that can be used to evaluate daily airtanker deployment strategies, but the optimization of daily deployment and re-deployment of airtankers calls for the solution of very computationally challenging stochastic dynamic programming models so they developed heuristics for solving the daily deployment and re-deployment problems. Chow and Regan (2011) [41•] drew on set covering location modelling methods to develop what is essentially a strategic homebasing type model they describe as a k-server p-median problem designed to allocate airtankers to bases in California over a 2-month fire season. They then developed a statistical model of day to day changes in fire weather and built on their season model to develop a dynamic chance-constrained model that can be used to help determine how best to re-deploy airtankers in California as the fire season progresses.

Others have exploited recent developments in stochastic integer programming (SIP) to develop more computationally tractable approaches to daily initial attack resource deployment optimization problems. Haight and Fried (2007) [42••] developed a SIP model to determine both how best to deploy initial resources at bases in order to maximize the number of initial attack fires that would subsequently receive a specified "standard response". In other words, some specified number of resources would arrive at the fire within a designated minimum time limit. More recently, Ntaimo et al. (2012) [43••] developed a SIP model that accounts for fire growth and suppression to determine how best to deploy dozers to bases in Texas for the fire season to best deal with fire loads that were characterized in the form of discrete scenarios that specified what sets of fires might be reported each day. They did so by explicitly modelling fire growth and indirect fire suppression action to determine the appropriate response for each fire. Arrubla et al. (2014) [44] subsequently developed a chanceconstrained SIP model in which they addressed the risk preferences of managers that deploy initial attack resources in Texas. Lee et al. (2013) [45•] extended the Haight and Fried (2007) [42••] model by using a set of seasonal fire scenarios and a more sophisticated procedure for specifying an appropriate response, to determine the optimal seasonal deployment of four types of suppression resources to three fire management units that can share their initial attack resources.

The recent advances in the use of SIP show considerable promise and may lead to the eventual development and implementation of more fully integrated approaches to the decision-making hierarchy that begins with weekly decisions concerning the sharing of suppression resources amongst geographically dispersed fire management agencies, the daily deployment of those resources, their subsequent dispatch to fires as they are reported and their use on the fire line. These are the challenging decisions that fire mangers must resolve but they will not adopt FMDSS that do not address their complex interactions adequately. That will call for advances in stochastic programming that can be addressed by the OR/MS research community and the development of more realistic fire suppression scenarios by OR/MS specialists working in collaboration with fire managers.

\section{Initial Attach Dispatch}

Each day, fire managers must decide what resources to dispatch to fires as they are reported. Such decisions are based on fire behaviour potential, values at risk, the availability of suppression resources and many other factors. They might, for example, dispatch fire trucks to moderate intensity readily accessible fires that do not pose an imminent threat to public safety or property and limit more costly airtanker and transport helicopter use to potentially more destructive fires that cannot be readily accessed by road. How well they resolve such decisions depends in part, upon the daily deployment decisions that were resolved earlier and higher in the decision-making hierarchy and must be based in part upon how those resources are expected to be used on the fire line. Most of the models that have been developed for such purposes contain relatively simple linkages to the subsequent suppression activities in which those resources will be engaged.

Donovan and Rideout (2003) [46••] appear to have been the first to formulate the initial attack dispatch problem as a deterministic integer linear programing (ILP) problem. Their objective was to determine which resources to dispatch to a fire with known attributes to minimize the net cost plus loss incurred as a result of the fire. 
Rideout et al. (2011) [47] extended Donovan and Rideout's (2003) [46••] deterministic single fire containment model to deal with multiple fires. They focussed on the dispatch of initial attack resources and developed a deterministic integer linear programming model designed to help determine which initial attack resources at which bases should be dispatched to a specified set of fires to minimize fire loss subject to a budget constraint over some finite planning horizon that could be a day, a week, or a fire season. Their approach is based on the assumption that one can predict in advance, fire occurrence scenarios that specify when and where all the fires that will require initial attack will occur and identify the need for further research to address that problem.

$\mathrm{Hu}$ and Ntaimo (2009) [48] extended Donovan and Rideout's (2003) [46*•] deterministic single fire model to develop a two-stage stochastic integer programming (SIP) model for optimizing the dispatch of initial attack resources to multiple fires under uncertainty. Uncertainty concerning fire occurrence and suppression needs was modelled using a discrete set of fire scenarios each of which can occur with some known or estimated probability. The first stage decision is which resources are to be dispatched to the fires, and the optimal use of those resources is identified in the second stage. Their SIP does not explicitly model the interaction of fire growth and suppression, but its output is linked to an agent-based simulation model that does model the interaction of fire growth and the suppression activities prescribed by the SIP model.

These optimization models constitute novel approaches to the very difficult problem of determining how best to dispatch initial attack resources to fires, but some of the modelling assumptions upon which they are based (e.g. that the attributes of all the fires requiring initial attack each day will be known to the dispatcher before he or she has to begin dispatching resources) and computationally tractability issues preclude their practical use for now.

\section{Containment and Large Fire Management}

Deciding how to contain a fire poses many challenges, all of which are complicated by uncertainty concerning weather and its impact on fire behaviour and suppression resource effectiveness. The term initial attack is typically used to describe the early stages of suppression and the resources that are allocated to the fire are referred to as the initial attack force. The resources used for initial attack vary by agency, and the determination of which resources to dispatch and the order in which they are dispatched to each fire varies by agency and by fire.

When the initial attack force includes airtankers, they often arrive over the fire shortly after the air attack officer arrives in a bird-dog aircraft and they will proceed to drop water or retardant on the fire under the direction of the air attack officer before fire trucks and/or ground crews arrive on site. When the ground crews do arrive some time later, either by air or by ground transport, the air attack officer will eventually hand the fire over to an incident commander (IC) who supervises the crew or crews that use pumps and hose, shovels and other equipment to construct control line around the fire. Airtankers may continue to work on portions of the fire not staffed by ground crews if they can drop their loads without jeopardizing the safety of the crews on the ground.

In the case of amphibious airtankers, the air attack officer must decide from which water body each airtanker will pick up water and when and where each airtanker will drop its load. On the ground, the IC must decide when and where to begin constructing control line using the equipment at his or her crews' disposal and how they will progress around the fire. The IC must assess the fuel, weather and topography and its impact on fire behaviour and suppression crew effectiveness, all the while keeping in mind that wind and other weather variables can and often do change dramatically. Since the safety of the fire crews is paramount, initial attack operations pose many complex decision-making challenges to the IC who must resolve his or her decisions under uncertainty.

Fires that are not contained by the initial attack force are variably classed as extended attack, escaped fires or large fires - the definition varies by agency. In the province of Ontario, for example, a fire is classed has having been successfully initially attacked if has been declared Being Held (BHEnot spreading) by noon on the day following the day the fire was reported, or its final size is less than or equal to 4 ha.

\section{Initial Attack}

The initial attack system is a crucial component of any fire management system and has been the subject of many attempts to develop FMDSS, one of the earliest of which was Parks (1964) [49]. Simard (1979) [50] developed a detailed simulation model of airtanker use on a single fire, but it was intended to serve as a research tool and not as a DSS for initial attack dispatchers. There have, of course, been many subsequent attempts to model the initial attack process (e.g. Fried and Fried, (1996) [51] and Plucinski (2013) [7]) but I am not aware of any initial attack DSS that have been implemented and documented in the peer-reviewed literature. It's especially interesting to note that Thompson et al. (2013) [52] concluded their comprehensive review of the effectiveness and efficiency of aircraft use in the US Forest Service by articulating a need for much better data and more comprehensive data to support new analytical initiatives in this area.

\section{Large Fire Management}

It has long been recognized that large fires constitute most of the area burned by wildfires and that their management consumes a large portion of most fire management agencies' 
budgets. Fire suppression expenditures have also been increasing for a number of reasons, some of which have been discussed in the peer-reviewed literature (e.g. Calkin et al. (2005) [53]). Some agencies, the USDA Forest Service in particular, have initiated many studies focussed on large fire management, one of the most recent of which is Thompson (2013) [54]. Nevertheless, the peer-reviewed literature suggests that many of the large fire management challenges that Shephard and Jewell (1961) [8] discussed when they first initiated research on the application of OR/MS to fire management remain. That being said, it has not been for lack of effort.

Martell (1982) [2] describes many of the early attempts to apply OR to large fire management, one of which was Bratten (1970) [55]. Mees et al. (1994) [56] developed a set of models that can be used to determine how to minimize the expected cost of containing a large fire subject to uncertainty concerning flame length and fire line construction productivity. More recent attempts have utilized the mathematical programming approaches that were first developed to address spatially explicit forest management planning to deal with the difficult problem of modelling the interaction of fire growth and fire line construction (e.g. Wei et al., 2011 [57•]).

The US Forest Service has, as noted above, long recognized the need to improve the management of large fires and in recent years, has supported research aimed at using information technology to develop information systems and FMDSS designed to meet the needs of large fire managers. Its Wildland Fire Decision Support System (WFDSS) which is described by Calkin et al. (2011) [58••] is a comprehensive FMDSS that can be used to support and document wildfire risk analysis to enhance the management of large, escaped fires. Finney et al.'s (2011) [59] ensemble stochastic fire growth modelling system is an important advance in providing fire managers with advanced fire growth technology but it, and models like it, ultimately have to be linked to tractable and realistic suppression optimization models that can be used to develop and evaluate alternative large fire suppression strategies and tactics on an operational basis.

That effective fire suppression can contribute to dangerous fuel buildups in many ecosystems, the so called fire paradox, has been the subject of growing interest in recent years (see for example, Regos et al. (2014) [60]). Coupled with that is the fact that the growth of large fires can sometimes be slowed when they burn into recent fire scars. Houtman et al. (2013) [61 ••] incorporated such factors in the methodology that they developed for estimating the potential impact of future fire suppression costs when a wildfire is allowed to burn. It illustrates both a need to and the possibility of exploiting advanced mathematical modelling methods to tackle some of the very complex fire management policy and operations that have come to complicate fire management in recent years.

\section{Looking to the Future}

OR/MS has made significant contributions to forest and wildland fire management, but many important challenges remain. The fire suppression that was practised by traditional fire control/exclusion agencies was relatively simple. Fire managers were expected to prevent, detect and suppress most fires, and since they were able to draw on emergency or extra fire fighting (EFF) funds, they were able to use whatever resources they could mobilize at almost any cost.

Modern fire management agencies face far more complex decision-making problems. The development of modern transportation and telecommunications systems have supported the creation of national and international collaborative agreements that make it possible for fire mangers to quickly mobilize much larger and more costly suppression forces than was ever the case in the past. Moreover, fire exclusion has been (and continues to be) gradually replaced by fire management and many fire mangers are experiencing and will continue to experience even more pressure to put and leave more fire on the landscape.

In their review of FMDSS, Mavsar et al. (2013) [30] pointed out the fact that the four strategic FMDSS they reviewed have been successfully used to enhance strategic fire management in North America, South America and Europe but lamented the fact that economic factors have not been fully incorporated in such FMDSS. I expect any fire ecologist, fire behaviour specialist or social scientist would share their sentiments with respect to the extent to which the knowledge that their disciplines have generated has been incorporated in such DSS as well. I expect there would also be widespread agreement upon the need for more basic research to further our understanding of the physical, ecological, economic and social processes that determine the social, economic and ecological impacts of fire and fire management.

Fire management is becoming increasingly complex and climate change, changing fuel complexes, land use patterns, societal expectations, and budget constraints will continue to complicate fire management even more. Fire managers and fire management can benefit from FMDSS that can be used to help organize such knowledge and quickly process it to predict and evaluate the potential impact of alternative strategies and tactics.

One of my greatest concerns, however, is that despite the fact that we expect fire managers to practise "science-based management", we do not provide them with enough of the science and technology they need to achieve what society expects of them. Forest and wildland fire managers will, in the absence of an adequate understanding of fire and its potential social, economic and ecological impacts and proven FMDSS they can use to enhance their decision-making, increasingly be forced to "risk manage" "by the seat of their 
pants". We can and must serve their needs much better than we have in the past.

Acknowledgments David Martell's fire research programme is supported by the Natural Sciences and Engineering Research Council of Canada (NSERC) and the Ontario Ministry of Natural Resources and Forests. A. Suksagar assisted with the compilation of the bibliographic material upon which this review is based and an anonymous reviewer and M. Alexander provided very helpful comments and suggestions on an earlier versions of this manuscript.

\section{Compliance with Ethics Guidelines}

Conflict of Interest David Martell declares that he has no conflicts of interest to declare.

Human and Animal Rights and Informed Consent This article contains no studies with human or animal subjects performed by the author.

\section{References}

Papers of particular interest, published recently, have been highlighted as:

- Of importance

-• Of major importance

1. Scott AC, Bowman DMJS, Bond WJ, Pyne SJ, Alexander ME. Fire on Earth: An Introduction. Chichester, Wiley-Blackwell; 2014.

2. Martell DL. A review of operational research studies in forest fire management. Can J For Res Rev Can Rech For. 1982;12:119-40.

3. Kalabokidis $\mathrm{KD}$, Gatzojannis S, Galatsidas S. Introducing wildfire into forest management planning: towards a conceptual approach. For Ecol Manag. 2002;158:41-50.

4. Rachaniotis NP, Pappis CP. Scheduling fire-fighting tasks using the concept of "deteriorating jobs". Can J For Res Rev Can Rech For. 2006;36:652-8. Models fire suppression as a scheduling problem.

5. Minas JP, Hearne JW, Handmer JW. A review of operations research methods applicable to wildfire management. Int J Wildland Fire. 2012;21:189-96.

6. Pacheco AP, Claro J, Oliveira T. Simulation analysis of the impact of ignitions, rekindles, and false alarms on forest fire suppression. Can J For Res. 2013;44:45-55.

7. Plucinski MP. Modelling the probability of Australian grassfires escaping initial attack to aid deployment decisions. Int J Wildland Fire. 2013;22:459-68.

8. Shephard RW, Jewell WS. Operations research in forest fire problems. In a study of fire problems. National Academy of SciencesNational Research Council, The Committee on Fire Research. Washington, DC; 1961.

9. Martell DL, Gunn EA, Weintraub A. Forest management challenges for operational researchers. Eur J Oper Res. 1998;104:1-17.

10. Martell DL. Fifty years of OR in forestry preface to the special forestry issue of INFOR. Infor. 2007;45:5-7.

11. Miller C, Ager AA. A review of recent advances in risk analysis for wildfire management. Int J Wildland Fire. 2013;22:1-14.

12. Pyne SJ. Fire in America: a cultural history of wildland and rural fire (Princeton. N.J.: Princeton University Press); 1982.

13. Pyne SJ. Awful splendour: a fire history of Canada. Vancouver, BC: UBC Press; 2007.
14. Prestemon JP, Butry DT, Abt KL, Sutphen R. Net benefits of wildfire prevention education efforts. For Sci. 2010;56:181-92. Innovative use of statistical methods to model fire prevention processes.

15. Ager AA, Day MA, McHugh CW, Short K, Gilbertson-Day J, Finney MA, et al. Wildfire exposure and fuel management on western US national forests. J Environ Manag. 2014;145:54-70.

16. Heineke JM, Weissenberger S. An analysis of wildfire prevention. IEEE Trans Syst Man Cybern Syst. 1974;SMC-4.

17. Mees RM. Computer evaluation of existing and proposed fire lookouts. General Technical Report PSW-19. Berkeley: U.S. Department of Agriculture, Forest Service, Pacific Southwest Forest and Range Experiment Station; 1976. 6 p.

18. Kourtz PH. A forest fire detection demand model—-for scheduling and routing of airborne detection patrols. Environment Canada, Canadian Forestry Service, Ottawa, Ontario. Departmental Publication 1322; 1973. 41 p.

19. Mahdipour E, Dadkhah C. Automatic fire detection based on soft computing techniques: review from 2000 to 2010. Artif Intell Rev. 2014;42:895-934.

20. Koltunov A, Ustin SL, Prins EM. On timeliness and accuracy of wildfire detection by the GOES WF-ABBA algorithm over California during the 2006 fire season. Remote Sens Environ. 2012;127:194-209.

21. Benkraouda S, Yagoubi B, Rebhi M, Bouziane A. Belonging probability inverse image approach for forest fire detection. Afr J Ecol. 2014;52:363-9.

22. Ko B, Kwak J-Y, Nam J-Y. Wildfire smoke detection using temporospatial features and random forest classifiers. Opt Eng. 2012;51.

23. Matthews S, Sullivan A, Gould J, Hurley R, Ellis P, Larmour J. Field evaluation of two image-based wildland fire detection systems. Fire Saf J. 2012;47:54-61.

24. Tapia G, Castillo M. System design of wildfire detection towers. Bosque. 2014;35:399-412.

25. Rego FC, Catry FX. Modelling the effects of distance on the probability of fire detection from lookouts. Int J Wildland Fire. 2006;15: 197-202. Use of distance sampling methods to model fire detection probability.

26. Martell DL, Davis LS, Weintraub A. editors. Proceedings: Workshop on Hierarchical Approaches to Forest Management in Public and Private Organizations. May 25-29, 1992. Petawawa National Forestry Institute. Information Report PI-X-124. (University of Toronto, Toronto, Ontario. Canadian Forest Service): Canada; 1996. p. 174.

27. Martell DL, Drysdale RJ, Doan GE, Boychuk D. An evaluation of forest fire initial attack resources. Interfaces. 1984;14:20-32.

28. McAlpine RS, Hirsch KG. An overview of LEOPARDS: the level of protection analysis system. For Chron. 1999;75:615-21.

29. Fried JS, Gilless JK, Spero J. Analysing initial attack on wildland fires using stochastic simulation. Int J Wildland Fire. 2006;15:13746.

30. Mavsar R, Caban AG, Varela E. The state of development of fire management decision support systems in America and Europe. For Policy Econ. 2013;29:45-55.

31. Pedernera P, Julio G, Usda U. Improving the economic efficiency of combatting forest fires in Chile: The KITRAL system. In Proceedings of Symposium on Fire Economics, Planning and Policy: Bottom Lines. 1999;173:149-155.

32. FPA. Fire Program Analysis (FPA). 2015.

33. Bruins RJF, Munns Jr WR, Botti SJ, Brink S, Cleland D, Kapustka $\mathrm{L}$, et al. A new process for organizing assessments of social, economic, and environmental outcomes: case study of wildland fire management in the USA. Integr Environ Assess Manag. 2010;6: 469-83. 
34. Greulich FE. A model for the seasonal assignment of air-tankers to home bases under optimal expected daily transfer rules. Berkeley, CA: University of California; 1976.

35. MacLellan JI, Martell DL. Basing airtankers for forest fire control in Ontario. Oper Res. 1996;44:677-86.

36. Donovan GH. Determining the optimal mix of federal and contract fire crews: a case study from the Pacific Northwest. Ecol Model. 2006;194:372-8.

37. Magnussen S, Taylor SW. Inter- and intra-annual profiles of fire regimes in the managed forests of Canada and implications for resource sharing. Int J Wildland Fire. 2012;21:328-41. National scale model of spatial and temporal autocorrelation of fire activity.

38.• Tsang A, Larson K, McAlpine R. Resource Sharing for Control of Wildland Fires. In Twenty-Seventh AAAI Conference on Artificial Intelligence. AAAI Publications; 2013. Model that captures important game-theoretic aspects of fire suppression resource sharing.

39. Islam KMS, Martell DL. Performance of initial attack airtanker systems with interacting bases and variable initial attack ranges. Can J For Res Rev Can Rech For. 1998;28:1448-55.

40. Islam KS, Martell DL, Posner MJ. A time-dependent spatial queueing model for the daily deployment of airtankers for forest fire control. Infor. 2009;47:319-33. Queueing model that captures spatial and temporal variation in initial attack systems.

41. Chow JYJ, Regan AC. Resource location and relocation models with rolling horizon forecasting for wildland fire planning. Infor. 2011;49:31-43. Novel approach to modelling airtanker deployment processes.

42.• Haight RG, Fried JS. Deploying wildland fire suppression resources with a scenario-based standard response model. Infor. 2007;45:31-9. Application of standard response model to wildland fire.

43.• Ntaimo L, Arrubla JAG, Stripling C, Young J, Spencer T. A stochastic programming standard response model for wildfire initial attack planning. Can J For Res Rev Can Rech For. 2012;42:9871001. Novel application of stochastic integer programing approach to initial attack planning.

44. Arrubla JAG, Ntaimo L, Stripling C. Wildfire initial response planning using probabilistically constrained stochastic integer programming. Int J Wildland Fire. 2014;23:825-38.

45. Lee Y, Fried JS, Albers HJ, Haight RG. Deploying initial attack resources for wildfire suppression: spatial coordination, budget constraints, and capacity constraints. Can J For Res Rev Can Rech For. 2013;43:56-65

Expanded scope initial attack deployment optimization model.

46.• Donovan GH, Rideout DB. An integer programming model to optimize resource allocation for wildfire containment. For Sci.
2003;49:331-5. Application of integer linear programming to fire suppression.

47. Rideout D, Wei Y, Kirsch A. Optimal allocation of initial attack resources to multiple wildfire events. Int J Saf Secur Eng. 2011;1: 312-25.

48. $\mathrm{Hu} \mathrm{X}$, Ntaimo L. Integrated simulation and optimization for wildfire containment. ACM Trans Model Comput Simul. 2009;19.

49. Parks GM. Development and application of a model for suppression of forest fires. Manag Sci. 1964;10:760-6.

50. Simard AJ. A computer simulation model of forest fire suppression with air tankers. Can J For Res. 1979;9:390-8.

51. Fried JS, Fried BD. Simulating wildfire containment with realistic tactics. For Sci. 1996;42:267-81.

52. Thompson MP, Calkin DE, Herynk J, McHugh CW, Short KC. Airtankers and wildfire management in the US Forest Service: examining data availability and exploring usage and cost trends. Int $\mathrm{J}$ Wildland Fire. 2013;22:223-33.

53. Calkin DE, Gebert KM, Jones JG, Neilson RP. Forest service large fire area burned and suppression expression trends, 1970-2002. J For. 2005; 103:179-83.

54. Thompson MP. Modeling Wildfire Incident Complexity Dynamics. Plos One. 2013;8(5):e63297.

55. Bratten FW. Allocation model for firefighting resources ... a progress report. Res. Note PSW-214. Berkeley: Department of Agriculture, Forest Service, Pacific Southwest and Range Experiment Station; 1970.

56. Mees R, Strauss D, Chase R. Minimizing the cost of wildland fire suppression - a model with uncertainty in predicted flame length and fire-line width produced. Can J For Res Rev Can Rech For. 1994;24:1253-9.

57. Wei Y, Rideout DB, Hall TB. Toward efficient management of large fires: a mixed integer programming model and two iterative approaches. For Sci. 2011;57:435-47. Large fire optimization model.

58.• Calkin DE, Thompson MP, Finney MA, Hyde KD. A real-time risk assessment tool supporting wildland fire decisionmaking. J For. 2011;109:274-80. Comprehensive risk management DSS.

59. Finney MA, Grenfell IC, McHugh CW, Seli RC, Trethewey D, Stratton RD, et al. A method for ensemble wildland fire simulation. Environ Model Assess. 2011;16:153-67.

60. Regos A, Aquilue N, Retana J, De Caceres M, Brotons L. Using unplanned fires to help suppressing future large fires in Mediterranean forests. PLoS One. 2014;9(4):e94906.

61.• Houtman RM, Montgomery CA, Gagnon AR, Calkin DE, Dietterich TG, McGregor S, et al. Allowing a wildfire to burn: estimating the effect on future fire suppression costs. Int $\mathrm{J}$ Wildland Fire. 2013;22:871-82. Novel approach to assessing the secondary impacts of large fire suppression. 